\title{
Black silicon as secondary standard of the black body
}

\author{
by R.F. Szeloch ${ }^{1}$, T.P. Gotszalk ${ }^{1}$, I. Rangelow ${ }^{2}$ and Z. Borkowicz ${ }^{1}$ \\ ${ }^{1}$ Institute of Microsystem Technology, Wroclaw University of Technology, Poland \\ ${ }^{2}$ Institute of Technical Physics, University Kassel, Germany
}

Abstract

One of the important problems in thermography of microsystems is scaling of the infrared radiation in very small areas. We describe an application of dry etched silicon surface, so called black silicon as the secondary standard of the black body in the Far Field Thermography (FFT). In our experiments the black silicon surface topography is studied with Scanning Electron Microscopy (SEM) and Atomic Force Microscope (AFM). Sample preparation is discussed also. Dependence of emission coefficient on temperature is studied in the wide temperature range and is compared with traditional black body model.

\section{Introduction}

Black silicon and other materials like for instance diamond-like carbon films are the materials which due to simplicity of their fabrication (simple technological process) and possibility of location of appropriate pre-prepared items on chips containing microsystems, are suitable for applications as secondary standards of black body. However, such applications require optimisation of technological process from the point of view of emission coefficient $\varepsilon$, whose value should be close to 1 .

Materials with emission and thus absorption coefficients close to 1 are also important components of radiation thermometers. Such material used as absorber of infrared sensor ensures relatively high response of the sensor [1].

In the work preliminary results of investigation on application of black silicon in thermographical studies of microsystems will be described.

\section{Process of fabrication and properties of black silicon}

Phenomena of random micromasking is often observed in such processes as Reactive lon Etching (RIE) in strong anisotropy conditions and selective silicon etching both in $\mathrm{SF}_{6} \mathrm{O}_{2}$ gas mixture with Al mask as well as in chlorine or chlorine containing gas.

The structure of black silicon is formed when the whole silicon surface is randomly covered with particles, clusters or other residues coming from reactor chamber walls, surface of cathode or material of masking layer. These elements define random microsurfaces which mask successfully some areas of silicon and cause that during etching process, a great number of densely packed needles microstructures originate and form a layer similar to dense grass on the silicon surface. In Fig. 1 a scheme of above described process of microcolumn etching is shown [2].

Physical properties of so formed surface of black silicon depend on the density of packaging of silicon needles (nanowires), their geometrical dimensions (diameter and height) and the depth of etching. Forming of black silicon has been considered as an interesting but side effect of the process of interaction of ions with silicon surface up to now, so the literature on this subject does not contain much information about its physical properties [2]. It is possible that the structure of numerous silicon high needles (nanowires) is a trap for incident and/or emitted infrared radiation. It may be assumed that emission or/and absorption coefficient of black silicon will rise with the increase of packaging density of nanowires, extension in etching depth and simultaneous decrease in the needles diameter. Due to the random character of the process, the final effect is determined by the average values of the above mentioned parameters. 
Exemplary images of black silicon surface obtained with scanning electron microscope (SEM) are shown in Fig. 2. Very interesting is the random character of resulted random structure, visible in Fig 2. Near the island of not etched silicon (Fig. $2 b$ - in the right side), some flat walls with random thickness comparable with the thickness of needles are formed. The remaining structure contains randomly located nanowires with various thickness. They form some clusters, connected with each other and/or with side walls.

In Fig. 3 similar structure of black silicon obtained by AFM with piezoresistive measuring cantilever [3] is shown. It is important to note the random character of surface structure of black silicon.

In Fig. 4 an experimental curve of radiation intensity of black silicon and equivalent model of micro black body are shown. The equivalent model of micro black body was made in form of a hole in the heating block (Fig. 5). Next to the hole, a wafer of black silicon was located. The measurements of infrared signal were made with a thermographic system described in [4]. With the system, the thermal image of thick-film heater with a standard of black body - black silicon - located on its surface was obtained (Fig. 6.). The method can be used for accurate determination of local temperature of microsystems.

\section{Conclusions}

Presented in the work, results of experiments confirm the hypothesis of the possibility of using of the structure of black silicon as a secondary standard of infrared radiation. The work on optimising the technological process, which aims at connecting the random geometrical structure of black silicon with its physical properties is being continued.

This work has been prepared as the pre-study for grant No 8T11B00615 sponsored by Scientific Research Committee (KBN).

\section{REFERENCES}

[1] BRUNETTI (L.). - Thin-film electrooptical property for FIR absolute radiometers. Sensors and Actuators A, 37-38, 1993, p. 521-526.

[2] RANGELOW (I.), THOREN (P.), MASSELI (K.), KASSING (R.), ENGELHARDT (M.), and SCHWARZL (S.). Secondary effects of single-etching in chlorine-containing plasma for 3-D capacitor. Microelectr. Eng., 5,1986, p.387-394.

[3] LINNERMANN (R.), GOTSZALK (T.) HADJIISKI (L.) and RANGELOW (1.). Characterisation of piezoresistive Wheatstone bridge cantilever. Thin Solid Films, 264, 1995 , p. 159.

[4] SZELOCH (R.F.), GUMIENNY (Z.), SOtTYSIAK (R), REGENCZUK (R). The high resolution IR system. Proc. of the 14-th Conf. of the ISHM Poland, Warsaw 1990 p.79-82. 
http://dx.doi.org/10.21611/qirt.1998.054

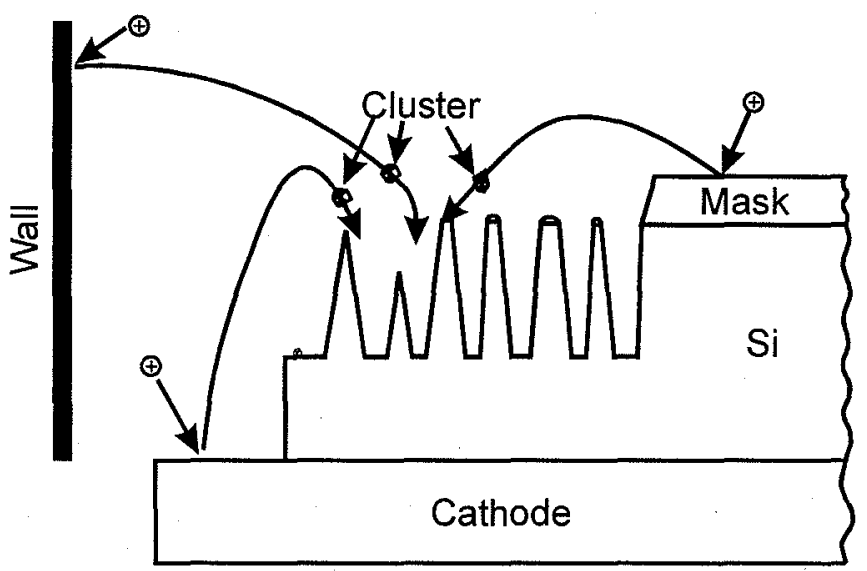

Fig. 1. Fabrication of "Black silicon"

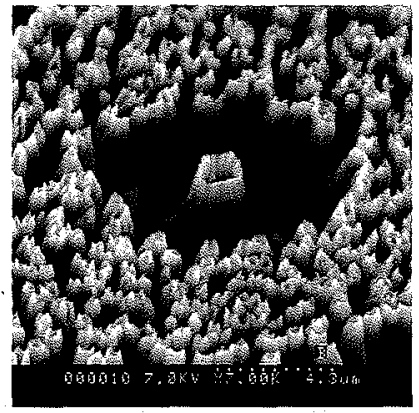

a)

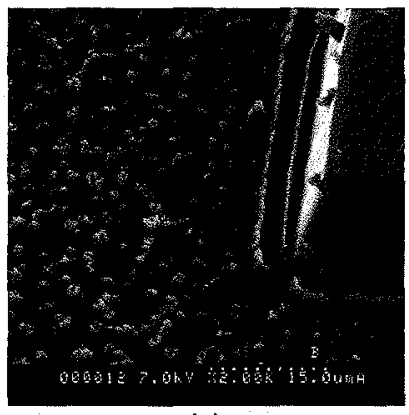

b)

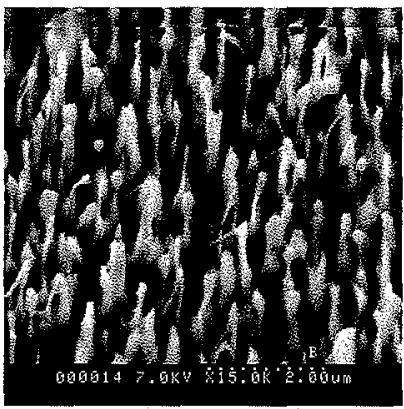

c)

Fig. 2. SEM micrographs of Black silicon. Textured surface quality depends of the pretreatment and plasma etching processes.

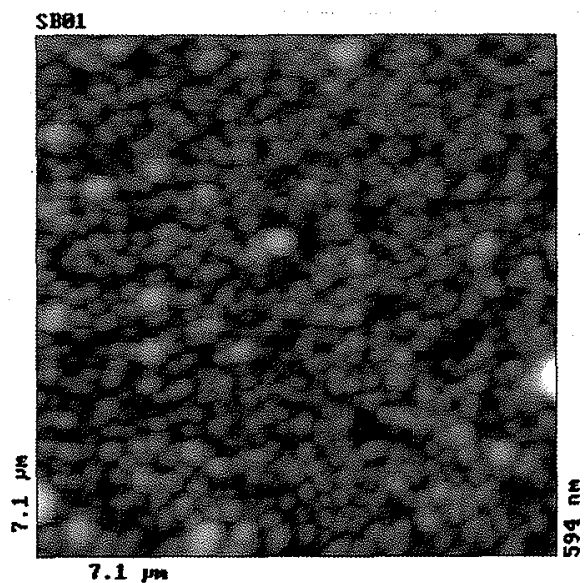

Fig. 3. Topography of the „Black silicon” structure measured with the contact AFM 
http://dx.doi.org/10.21611/qirt.1998.054

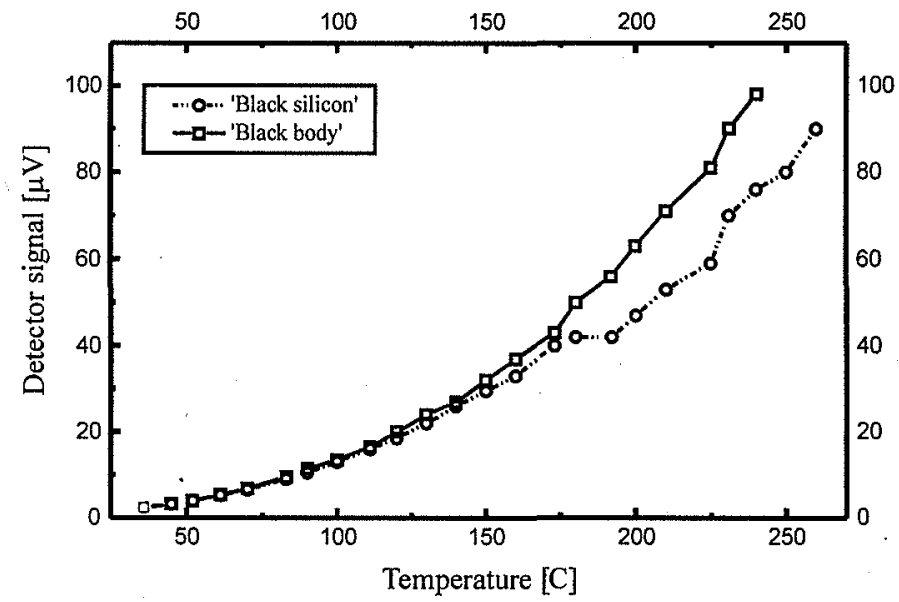

Fig. 4 IR intensity of the „Black silicon” structure measured with system described in [2]

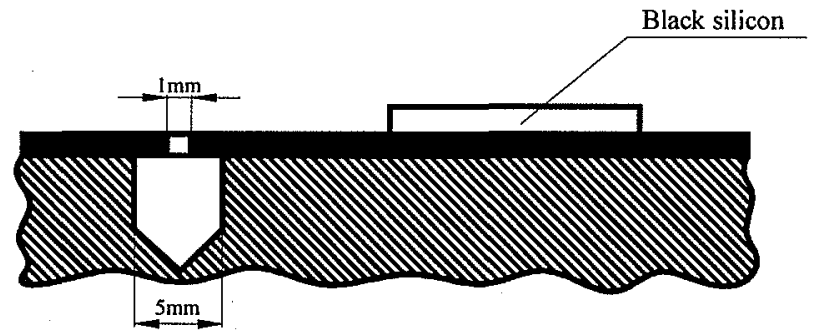

Fig. 5. Micro "Black body" and "Black silicon"

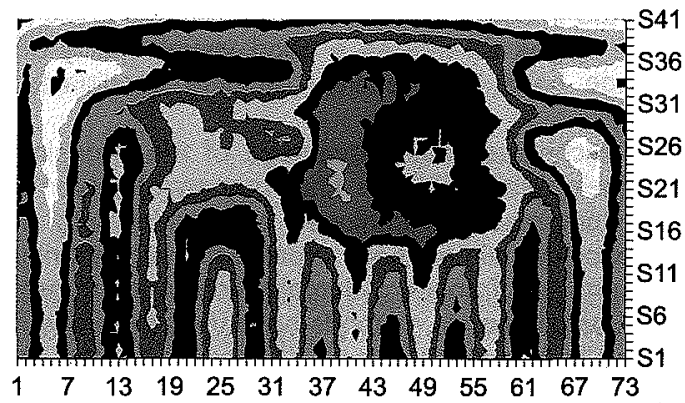

\begin{tabular}{|c|}
\hline $1,00 \mathrm{E}-03-1,05 \mathrm{E}-03$ \\
\hline$, 50 \mathrm{E}-04-1,00 \mathrm{E}-03$ \\
\hline $0 \mathrm{E}-04-9,50 \mathrm{E}$ \\
\hline 圆8,50E-04-9,00E-0 \\
\hline $8,00 \mathrm{E}-04-8,50 \mathrm{E}-$ \\
\hline $7,50 \mathrm{E}-04-8,00 \mathrm{E}-0$ \\
\hline $7,00 \mathrm{E}-04-7,50 \mathrm{E}-0$ \\
\hline 图 6,50E-04-7,00E-c \\
\hline $5,00 \mathrm{E}-04-6,50 \mathrm{E}-0$ \\
\hline $0 \mathrm{E}-04-6,00 \mathrm{E}$ \\
\hline$, 00 E-04-5,50$ \\
\hline
\end{tabular}

Fig. 6. Thermographic image of the thick film heater with "Black silicon" 